\title{
Recall of diagnosis by men with ischaemic heart disease
}

\author{
A G SHAPER, D G COOK, M WALKER, P W MACFARLANE`
}

From the Department of Clinical Epidemiology and General Practice, Royal Free Hospital School of Medicine, London; and the *University Department of Medical Cardiology, Royal Infirmary, Glasgow

SUMMARY In a study of the prevalence of ischaemic heart disease in middle aged men in 24 British towns, the subjects were asked whether a doctor had ever told them that they had any form of cardiovascular disease. Their recall of various diagnoses was related to evidence of ischaemic heart disease obtained by an administered questionnaire on chest pain and electrocardiography. Twenty one per cent of men recalled a diagnosis of cardiovascular disease, in one quarter of whom it was ischaemic heart disease. There was a sixfold increase in the prevalence of recall of a diagnosis of ischaemic heart disease over the age range studied. Only one third of the men with possible myocardial infarction on questionnaire recalled such a diagnosis having been made by a doctor. Only half of those with a definite myocardial infarction on an electrocardiogram could recall a diagnosis of ischaemic heart disease. Even in severe (grade 2) angina $40 \%$ could not recall being told that they had heart disease. Overall, only one in five of those regarded as having ischaemic heart disease was able to recall such a diagnosis having been made by a doctor, and these were likely to be those most severely affected. Ischaemic heart disease is common in middle aged British men, but most of those affected are apparently not aware of their condition. This low level of awareness among patients and doctors may contribute to a lack of public concern regarding the need for action to reduce the incidence of ischaemic heart disease in Great Britain.

Ischaemic heart disease is extremely common in middle aged men in Great Britain and is a major cause of death. ${ }^{1}$ In a recent study of 7735 men aged 40-59 years, drawn from general practices in 24 towns in England, Wales, and Scotland, one quarter had some evidence of ischaemic heart disease on a questionnaire on chest pain or on electrocardiography. ${ }^{2}$ In this study we examined the awareness of these men concerning the disease by which they are affected and indirectly assessed how much of this burden of illness in the population is apparently recognised by medical practitioners.

\section{Subjects and methods}

The British Regional Heart Study includes 7735 men aged 40-59 years randomly selected from the age-sex registers of group general practices in 24 towns in

Requests for reprints to Professor A G Shaper, Department of Clinical Epidemiology and General Practice, Royal Free Hospital School of Medicine, Rowland Hill Street, London NW3 2PF.

Accepted for publication 10 January 1984
England, Wales, and Scotland. The criteria for selecting the town, the general practice, and the subjects, as well as the methods of data collection, have been reported previously. ${ }^{3}$ From each age-sex register some 420 men aged 40-59 years were selected at random to produce five-year age groups of equal size. The list of names was reviewed by the doctors in the practice, who were asked to exclude those whom they considered would not be able to participate because of severe mental or physical disability. It was emphasised that no attempt should be made to exclude subjects with cardiovascular problems, and close scrutiny of the returned annotated lists reduced the exclusions to approximately 6 to 10 per practice. The remaining subjects were invited to take part in the study in a letter signed by the general practitioners, and on average $78 \%$ of those invited attended for examination.

A mobile research team of three nurses administered to each man an extensive questionnaire which included questions on chest pain ${ }^{4}$ and medical history. The questions on chest pain were based on the WHO questionnaire, ${ }^{4}$ but they are not identical. Copies of the questionnaire are available on request. Electrocardiograms were recorded on all subjects using the three orthogonal lead system. ${ }^{2}$ 
CRITERIA AND CATEGORIES

Diagnosis recall

The patient was asked "Have you ever been told by a doctor that you have, or have had . . . ?" (any one or more of a number of conditions, including angina, heart attack, coronary thrombosis, myocardial infarction, "other heart trouble," high blood pressure, and stroke). In this report reference will be made to angina and myocardial infarction, the latter term including those who said yes to any one of the questions regarding heart attack, coronary thrombosis, or myocardial infarction. "Other heart trouble" will be discussed only in relation to those men who did not recall a diagnosis of angina or myocardial infarction. It must be strongly emphasised that the term "recall of diagnosis" is a summary expression for the complex procedure by which a patient seeks attention from a doctor, is given a diagnosis, comprehends it in a variety of possible ways, and then recalls it at a time which may be years after the initial event. The absence of recall of diagnosis in the context of this paper clearly does not mean that a doctor has failed to make a diagnosis when he might have done so.

\section{Questionnaire on chest pain}

Possible myocardial infarction-Subjects were regarded as having had a possible myocardial infarction if $(a)$ they answered yes to "Have you ever had a severe pain in your chest lasting for half an hour or more?" and $(b)$ the distribution of pain included the sternal area or left upper chest. ${ }^{2}$ Those with severe chest pain not involving any one of these sites were included in "other chest pain." All men with prolonged severe chest pain were asked whether they had seen a doctor because of this pain.

Angina-Subjects were regarded as having definite angina if they answered yes to $(a)$ "Do you ever have any pain or discomfort in your chest?" and to $(b)$ "When you walk uphill or hurry, does this produce pain?" In addition, four further criteria had to be satisfied: (i) the distribution of pain included the sternal area or left upper chest, (ii) the subject slowed down or stopped walking when the pain occurred; (iii) the pain went away if he stood still and (iv) did so in less than 10 minutes. These criteria denote definite angina grade 1 . If in addition, the chest pain was produced by walking at an ordinary pace on the level it was regarded as grade 2 . If all the four additional criteria were not fulfilled possible angina was recorded, and this was also separated into grades 1 and 2. Chest pain not related to exertion was included in the "other chest pain" category.

\section{Electrocardiogram}

Details of the three orthogonal lead electrocardiogram have previously been provided, and the relation between the classification used for this system and the Minnesota Code widely used for classifying 12 lead electrocardiograms has been outlined. ${ }^{2}$ For the purposes of this study, a system of exclusive categories in ranking order was used so that each man appears only once in the analysis of the findings-namely, $(a)$ definite myocardial infarction, $(b)$ possible myocardial infarction, $(c)$ definite myocardial ischaemia, and $(d)$ possible myocardial ischaemia. Electrocardiographic evidence of left bundle branch block was equated with (d), and other electrocardiographic abnormalities such as ventricular hypertrophy were ignored for the purposes of this study.

\section{Terminology}

In order to make it clear which method is being referred to at any particular time the suffixes (DR), (Q), and (ECG) are used whenever necessary to refer respectively to diagnosis recall, to the questionnaire on chest pain, and to the electrocardiographic findings. Angina (DR) and myocardial infarction (DR) may be combined as ischaemic heart disease (DR). Definite angina $(Q)$ and possible angina $(Q)$ may be combined as angina $(Q)$. Angina $(Q)$ and possible myocardial infarction (Q) may be combined as ischaemic heart disease $(Q)$. The electrocardiographic findings of definite or possible myocardial infarction and definite or possible myocardial ischaemia may be combined as ischaemic heart disease (ECG). The term "ischaemic heart disease" without a suffix is used in the general sense.

\section{Results}

\section{DIAGNOSIS RECALL}

In $424(5.5 \%)$ men there was a history of a doctor having told them that they had angina or a heart attack (myocardial infarction, coronary thrombosis) or both (Table 1). A further $471(6 \cdot 1 \%)$ men recalled having been told that they had "other heart trouble." High blood pressure had been diagnosed by a doctor in 989 ( $13 \%$ of the total) and stroke in $52(0.7 \%)$. Both

Table 1 Recall of diagnosis of heart disease, high blood pressure, and stroke

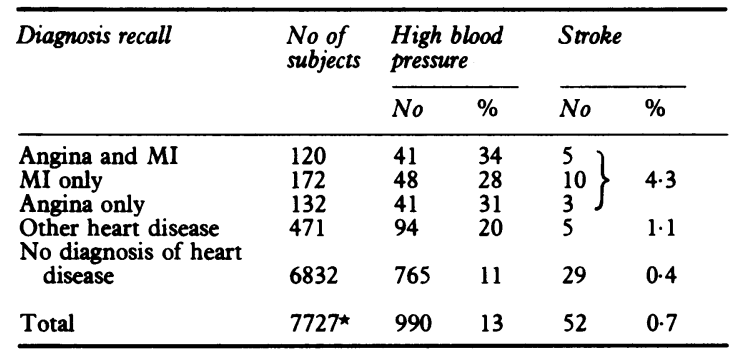

MI, myocardial infarction. $\star$ Data missing on eight men. 
of these latter conditions will be dealt with in a subsequent report relating these findings to blood pressure measurements made at examination in these men. It is evident, however, that recall of a diagnosis of high blood pressure is three times as frequent in men who recall a diagnosis of ischaemic heart disease and twice as frequent in those with "other heart disease," as in men with no recall of a diagnosis of heart disease.

Those with "other heart disease" were separated into four groups using information obtained by the research nurses administering the questionnaire: $(a)$ the rheumatic heart/valve disease group (264), including rheumatic fever, rheumatic heart disease, all forms of valve disease, valve operations, and "murmurs"; (b) the palpitations/arrhythmia group (82), including any form of irregular pulse and the occasional pacemaker; $(c)$ possible ischaemic heart disease (52), comprising a collection of vague terms relating to the heart ("weak," "strained," "suspect"); and (d) the miscellaneous/uncertain group (73), including pericarditis, myocarditis, cor pulmonale, problems dating from birth (not murmurs), and those descriptive terms which could not be included in any of the other three categories.

\section{QUESTIONNAIRE RESPONSE AND DIAGNOSIS}

\section{RECALL}

In men with possible myocardial infarction (Q) or angina $(Q)$ the frequency of recall of such a diagnosis having been made by a doctor is shown in Table 2 .

This Table shows that in men with possible myocardial infarction $(Q)$ as well as angina $(Q)$ three quarters recalled a diagnosis of ischaemic heart disease by a doctor. In those with possible myocardial infarction $(Q)$ only or definite angina $(Q)$ only one quarter recalled a diagnosis of ischaemic heart disease by a doctor. The rate of diagnosis recall fell to $12 \%$ in those with possible angina $(\mathrm{Q})$, to $2 \%$ in those with "other chest pain," and to $0.5 \%$ in men with no history of chest pain. More specifically only one third of the 703 men with possible myocardial infarction (Q) were able to recall having been told by a doctor that they had suffered a heart attack, even though $88 \%$ had reported the episode to a doctor.

The grade of angina on questionnaire, not unexpectedly, affected the likelihood of a diagnosis of ischaemic heart disease being made by the doctor. If the angina were more severe (grade 2) a diagnosis of ischaemic heart disease by a doctor was much more likely than if it were grade 1 angina. Even in men with grade 2 angina, however, $40 \%$ did not recall having been told by a doctor that they had ischaemic heart disease (data not presented).

Table 2 shows how frequently the recall of a diagnosis of ischaemic heart disease made by a doctor was supported by the questionnaire findings. In men with a diagnosis recall of myocardial infarction combined with angina $98 \%$ were diagnosed as having ischaemic heart disease by questionnaire. In those with myocardial infarction (DR) only or angina (DR) only the questionnaire recorded ischaemic heart disease in approximately $80 \%$. In the "other heart disease"

Table 2 Recall of diagnosis in relation to response to questions on chest pain and electrocardiographic findings. Figures are numbers of subjects

\begin{tabular}{|c|c|c|c|c|c|c|c|}
\hline & \multicolumn{7}{|c|}{ Diagnosis recall } \\
\hline & $\begin{array}{l}\text { MI and } \\
\text { angina }\end{array}$ & MI only & Angina only & $\begin{array}{l}\text { Other heart } \\
\text { disease }\end{array}$ & $\begin{array}{l}\text { No heart } \\
\text { disease }\end{array}$ & Total & $\begin{array}{l}I H D(D R) \\
(\%)\end{array}$ \\
\hline $\begin{array}{l}\text { Possible MI and angina } \\
\text { Possible MI only } \\
\text { Definite angina only } \\
\text { Possible angina only } \\
\text { Other chest pain } \\
\text { No chest pain }\end{array}$ & $\begin{array}{l}85 \\
19 \\
10 \\
3 \\
3 \\
0\end{array}$ & $\begin{array}{l}45 \\
83 \\
7 \\
3 \\
18 \\
15\end{array}$ & $\begin{array}{l}34 \\
14 \\
43 \\
13 \\
16 \\
11\end{array}$ & $\begin{array}{l}r e \\
14 \\
36 \\
18 \\
19 \\
151 \\
232\end{array}$ & $\begin{array}{l}38 \\
335 \\
151 \\
123 \\
1650 \\
4523\end{array}$ & $\begin{array}{l}216 \\
487 \\
229 \\
161 \\
1838 \\
4781\end{array}$ & $\begin{array}{l}76 \\
24 \\
26 \\
12 \\
2 \\
0 \cdot 5\end{array}$ \\
\hline Total & 120 & 171 & 131 & 470 & 6820 & $7712^{\star}$ & - \\
\hline \% With IHD (Q) & 98 & 81 & $\begin{array}{c}79 \\
\text { Electrocardiograpl }\end{array}$ & $\begin{array}{l}19 \\
\text { c findings }\end{array}$ & 9 & - & - \\
\hline $\begin{array}{l}\text { Definite MI } \\
\text { Possible MI } \\
\text { Definite ischaemia } \\
\text { Possible ischaemia } \\
\text { None of the above }\end{array}$ & $\begin{array}{l}34 \\
4 \\
14 \\
15 \\
53\end{array}$ & $\begin{array}{l}72 \\
6 \\
15 \\
11 \\
68\end{array}$ & $\begin{array}{l}8 \\
5 \\
10 \\
14 \\
95\end{array}$ & $\begin{array}{l}17 \\
6 \\
20 \\
28 \\
400\end{array}$ & $\begin{array}{l}111 \\
65 \\
198 \\
471 \\
5979\end{array}$ & $\begin{array}{l}242 \\
86 \\
257 \\
539 \\
6595\end{array}$ & $\begin{array}{l}47 \\
17 \\
15 \\
7 \\
3\end{array}$ \\
\hline Total & 120 & 172 & 132 & 471 & 6824 & $7719+$ & - \\
\hline$\%$ With IHD (ECG) & 56 & 60 & 28 & 15 & 12 & - & - \\
\hline
\end{tabular}

MI, myocardial infarction; IHD, ischaemic heart disease; DR, diagnosis recall; $Q$, questionnaire.

$\star$ Recall data, questionnaire data, and both data missing on eight, 15, and one man respectively.

tRecall data and electrocardiographic data missing on eight men each. 
category $19 \%$ had a history of significant chest pain on questionnaire, and $9 \%$ of those with no diagnosis recall of any heart disease had some evidence of ischaemic heart disease $(\mathrm{Q})$.

ELECTROCARDIOGRAPHIC FINDINGS AND RECALL OF DIAGNOSIS

Table 2 shows that a diagnosis recall of ischaemic heart disease was made in $47 \%$ of the 242 men with a definite myocardial infarction (ECG) compared with in $3 \%$ of those with no electrocardiographic evidence of ischaemic heart disease. Thus more than half of those with definite electrocardiographic evidence of myocardial infarction had either not presented for diagnosis, had not been diagnosed as having ischaemic heart disease by a doctor, or could not recall the event.

To what extent is the recall of a diagnosis of ischaemic heart disease supported by the electrocardiographic findings? Our data are not really suitable for this purpose as the event and the diagnosis may have taken place many years ago, and a previously abnormal electrocardiogram may have returned to normal. Nevertheless, in men who recalled a doctor diagnosis of myocardial infarction (with or without angina) $56-60 \%$ had electrocardiographic evidence of ischaemic heart disease compared with $12 \%$ in those who did not recall a diagnosis of ischaemic heart disease ever having been made by a doctor.

\section{QUESTIONNAIRE, ELECTROCARDIOGRAM, AND DIAGNOSIS RECALL}

How much of the ischaemic heart disease observed in this study has been recognised by doctors? We have no direct measure of this, but we do have a measure of each man's ability to recall whether a doctor had ever told him that he had ischaemic heart disease-that is, a heart attack, myocardial infarction, coronary thrombosis, or angina. The Figure shows the frequency of diagnosis recall of ischaemic heart disease according to the criteria used in this study for establishing the diagnosis-that is, angina $(Q)$, possible myocardial infarction $(Q)$, or electrocardiogram. In those with angina (Q) only or possible myocardial

Table 3 Recall of diagnosis by age. Figures are percentages of subjects ${ }^{\star}$

\begin{tabular}{lllll}
\hline \multicolumn{5}{c}{ Age range (yr) } \\
\cline { 2 - 5 } $\begin{array}{l}\text { Diagnosis } \\
\text { recall }\end{array}$ & $\begin{array}{l}40-44 \\
(n=1836)\end{array}$ & $\begin{array}{l}45-49 \\
(n=1896)\end{array}$ & $\begin{array}{l}50-54 \\
(n=1972)\end{array}$ & $\begin{array}{l}55-59 \\
(n=2023)\end{array}$ \\
\hline $\begin{array}{l}\text { Ischaemic heart } \\
\text { disease }\end{array}$ & 1.6 & 3.2 & 6.8 & 9.8 \\
$\begin{array}{l}\text { "Other heart } \\
\text { disease" }\end{array}$ & 5.8 & 4.9 & 7.2 & 6.5 \\
\hline
\end{tabular}

$\star$ Data missing on eight men.

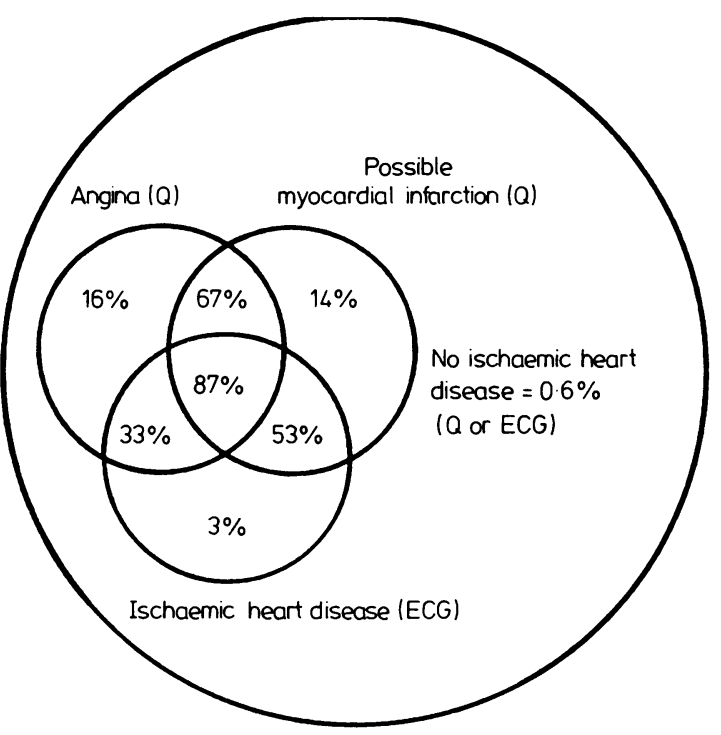

Figure. Recall of diagnosis of ischaemic heart disease by a doctor in various diagnostic categories.

infarction (Q) only $14-16 \%$ recalled a diagnosis of ischaemic heart disease made by a doctor. If, in addition, they had a positive electrocardiogram the frequency of diagnosis recall increased considerably, to $33 \%$ and $53 \%$ respectively. This suggests that the disease was more severe and that symptoms were more impressive. If both angina $(\mathrm{Q})$ and possible myocardial infarction $(Q)$ were present recall of diagnosis was high $(67 \%)$, and the presence of a positive electrocardiogram increased diagnosis recall even further (87\%). Not surprisingly, a positive electrocardiogram without a history of chest pain achieved a low rate of diagnosis recall $(3 \%)$.

Of the 422 men with a diagnosis recall of ischaemic heart disease, only $36(0.6 \%)$ did not have questionnaire or electrocardiographic evidence of ischaemic heart disease. Of the 1901 men who had evidence of ischaemic heart disease on questionnaire or electrocardiogram or both, only one in five could recall a diagnosis of ischaemic heart disease made by a doctor.

AGE AND PREVALENCE OF DIAGNOSIS RECALL

There is a progressive increase in the prevalence of the recall of diagnosis of ischaemic heart disease with increasing age, sixfold over the age range in this study. "Other heart disease" shows no increase with age over the age range studied (Table 3 ).

\section{Discussion}

The ability to recall that a doctor had made a diagnosis of a specific condition-for example, a heart 
attack or angina-depends on a number of factors. These include the doctor's intention and ability to communicate the information and the patient's ability to understand and recall what the doctor said at the time. The number of variables, including the passage of time, that can affect an individual's ability to recall a diagnosis made by a doctor are considerable and complex. ${ }^{5}$ As the time between an event and the interview increases there is increased under-reporting of the event. Events that are important to the individual are reported more accurately and recalled more frequently than those of lesser significance. The more visits made for a condition, the longer the hospitalisation, or the greater the impact on the patient's behaviour the more likely it is to be recalled. If an event is perceived as threatening, however, to life or self-image it is likely not to be reported at all or to be modified in some desirable direction. A study in the United States of under-reporting of hospital episodes involving 1500 people in 21 hospitals (1958-9) showed an overall under-reporting of $12 \%$. Heart diseases (13\%) were not particularly under-reported when compared with mental/personality disorders (32\%), infective/parasitic diseases (22\%), neoplasms (23\%), and diseases of the central nervous system (17\%). 6

There appear to be no directly comparable studies of under-reporting which relate specifically to cardiovascular disease in general practice in Great Britain. It would seem reasonable, however, to assume that some degree of under-reporting is taking place in the Regional Heart Study. Nevertheless, it seems worthwhile to inquire of individuals whether they are aware of diagnostic labels which might have been attached to them, for this knowledge may affect their personal behaviour and could condition their general attitudes to the health of their community. In this population of middle aged men drawn at random from the registers of general practices in 24 British towns, $21 \%$ were able to recall a diagnosis of at least one cardiovascular disorder-for example, angina, high blood pressure, stroke. About one quarter of these men recalled a specific diagnosis of ischaemic heart disease, and because they had all completed an administered questionnaire on chest pain and had an electrocardiogram recorded it was possible to apply a form of internal validation to their recall of diagnosis. Not surprisingly, if a man recalled a diagnosis of myocardial infarction and angina internal validation by questionnaire was almost complete $(98 \%)$, and even in those with myocardial infarction or angina only it was high $(80 \%)$ : Validation of diagnosis recall by electrocardiogram was less impressive, and only $59 \%$ of men who recalled a diagnosis of myocardial infarction had evidence of ischaemic heart disease (ECG). In those with a diagnosis recall of angina only $28 \%$ had ischaemia on an electrocardiogram. When the ability of the electrocardiogram to return to normal over time in subjects who experience a myocardial infarction ${ }^{7}$ and the limited ability of a resting electrocardiogram to detect myocardial ischaemia are taken into account, ${ }^{8}$ these findings may probably be regarded more favourably.

The fact that only one third of the men with possible myocardial infarction ( $Q$ ) were able to recall a doctor's diagnosis of heart attack is of considerable interest. It could suggest that the diagnosis is being made with caution or reluctance, and indeed it is known that the vast majority of these men consulted a doctor regarding their severe chest pain. Even in men with severe angina an impressive minority ( $40 \%)$ did not recall having been told that they had ischaemic heart disease. As it is unlikely that these men had not reported their condition to a doctor at one time or another, this again suggests caution on the part of the doctor in making the diagnosis or in communicating it to the patient.

The electrocardiographic findings also illuminate the problems of diagnosis. More than half of the men with definite myocardial infarction on electrocardiogram did not recall a diagnosis of heart attack having been made, although we know that two thirds (65\%) of them had experienced chest pain of some kind. There is considerable awareness of the "unrecognised" myocardial infarction, and these findings may be interpreted as strong support for the concept that for every myocardial infarction that is clinically manifest there is one that is silent. ${ }^{9}$

Overall, $25 \%$ of the men in this study were regarded as having some evidence of ischaemic heart disease. In $4 \%$ of all the men there was evidence from the electrocardiogram and the chest pain questionnaire, in $10 \%$ from the questionnaire only, and in $11 \%$ from the electrocardiogram only. ${ }^{2}$ Only one in five of those with ischaemic heart disease (ECG or $Q$ or both), however, recalled a diagnosis by a doctor of the condition, suggesting that there is either a failure to report chest pain to the doctor, considerable underdiagnosis of the disorder, an unwillingness to communicate the diagnosis to the patient, or a remarkable inability of men to recall the diagnosis of a major chronic disease.

The data in the Figure suggest that it is symptoms of chest pain that bring the patient to the doctor but that it is the severity of the underlying disease that determines the likelihood of a definite diagnosis being made and communicated to the patient. Severity, in this study, is manifest either by the combined presence of angina and possible myocardial infarction on questionnaire or by angina or possible myocardial infarction ( $Q$ ) accompanied by a positive electrocardiogram or both. In clinical practice, as opposed to a survey of this kind, these "severe" cases will presum- 
ably present with additional features (for example, breathlessness), which make the doctor more certain of a diagnosis of ischaemic heart disease and more ready to inform the patient of his opinion.

It is recognised that people in Great Britain are very much less aware of the factors associated with ischaemic heart disease than their counterparts in the United States of America. ${ }^{10}$ It has been suggested that increasing public awareness of the size of the problem in the United States and increased knowledge of the postulated risk factors have been responsible, at least in part, for the reduction in mortality from ischaemic heart disease apparent in that country. " Perhaps if people in Great Britain were more aware of the high prevalence of ischaemic heart disease they would urge greater action towards measures designed to lessen the burden of disease. This study shows that there is a remarkable unawareness among the men with ischaemic heart disease of their own problem. When this is combined with a similar unawareness by doctors of the true prevalence of the disease and caution on the part of doctors in labelling patients as having ischaemic heart disease it makes for a widespread lack of concern regarding the need for action.

The British Regional Heart Study is supported by a programme grant from the Medical Research Council. We deeply appreciate the dedicated work of the team of research nurses who carried out the survey and those members of the Regional Heart Study team responsible for the organisation and analysis of the data. Dr Nicholas Cohen, senior research fellow and codirector 1977-78, made considerable contribution to the design and development of the survey. Dr Stuart Pocock (statistician) and Dr Dag Thelle (Tromsø, Norway, visiting epidemiologist) played an important role in the development of this paper. We are grateful to all the general practitioners and their staff for their willing collaboration.

\section{References}

1 Office of Population Censuses and Surveys. Mortaiity statistics, England and Wales 1981. London: HMSO, 1982.

2 Shaper AG, Cook DG, Walker M, Macfarlane PW. Prevalence of ischaemic heart disease in middle aged British men. Br Heart $\mathcal{F}$ 1984; 51: 595-605.

3 Shaper AG, Pocock SJ, Walker M, Cohen NM, Wale CJ, Thomson AG. British Regional Heart Study: cardiovascular risk factors in middle-aged men in 24 towns. $\mathrm{Br}$ Med F 1981; 283: 179-86.

4 Rose GA, Blackburn H, Gillum RF, Prineas RJ. Cardiovascular survey methods. 2nd ed. Geneva: World Health Organisation, 1982.

5 Cannell CF, Miller PV, Oksenberg L. Research on interviewing techniques. In: Leinhardt $S$, ed. Sociological methodology. San Francisco, California: Jossey-Bass, 1981: $389-437$.

6 US National Health Survey. Reporting of hospitalisation in the health interview. Washington, DC: US Department of Health, Education and Welfare, Public Health Service, 1961.

7 Kaplan BM, Berkson DM. Serial electrocardiograms after myocardial infarction. Ann Intern Med 1964, 60: 430-5.

8 Robb GP, Marks HH, Mattingly TW. Stress tests in the detection of coronary disease. Posgrad Med 1958; 24: 419-30.

9 Anonymous. Unrecognised myocardial infarction. Lancet 1976; ii: 449-50.

10 Yanchinski S. Britain batters its way to heart disease. New Scientist 1981; 92: 223.

11 Havlik RJ, Feinleib M, eds. Proceedings of the conference on the decline in coronary heart disease mortality. Bethesda, Maryland: US Department of Health, Education and Welfare, 1979. 